\title{
Tribunal Constitucional Internacional - auto de ciência
}

\author{
Gonçalo S. de Melo Bandeira ${ }^{12}$
}

\begin{abstract}
Resumo: a criação dum Tribunal Constitucional Internacional, no nosso entender, é uma exigência da própria Declaração Universal dos Direitos do Homem de 1948. Neste texto são apresentados uma série de argumentos velhos e novos para a importância da existência do Tribunal Constitucional Internacional a nível mundial. Trata-se dum Tribunal que é indispensável à defesa dos Direitos do Homem, contra qualquer tipo de ditadura ou fanatismo económico, social, político, cultural ou mental.

Palavras Chave: Tribunal Constitucional Internacional; Direito Constitucional; Direitos Humanos; Estado de Direito democrático, livre e verdadeiro.
\end{abstract}

Abstract: the creation of an International Constitutional Court, in our view, is a requirement of own Universal Declaration of Human Rights of 1948. In this paper are given a lot of old and new arguments for the importance of the existence of the International Constitutional Court worldwide. It is of a Court that is indispensable to the defense of human rights, against all forms of dictatorship or economic fanaticism, social, political, cultural or mental.

Keywords: International Constitutional Court; Constitutional right; Human rights; Democratic rule of law, free and true.

\section{1 - Introdução: objectivos e metodologia}

Os objectivos são demonstrar a inegável pertinência que a existência de um Tribunal Constitucional (Constitucional) ${ }^{3}$ Internacional pode ter na contribuição para uma mundialização - em contraponto a uma globalização do capitalismo selvagem de acordo como os Direitos Humanos. Desde logo, não podemos deixar de invocar a Declaração Universal dos Direitos do Homem (DUDH) de 1948 como uma das referências básicas fundamentais deste futuro Tribunal. A DUDH de 1948 é aliás, a título de bom exemplo, aplicada de modo directo no ordenamento jurídico português, quer através do art. $8^{\circ}$ da Constituição da República Portuguesa (CRP), quer por intermédio do art. $16^{\circ}$ da também CRP, quanto ao âmbito e sentido dos direitos fundamentais: "1. Os direitos fundamentais consagrados na Constituição não excluem quaisquer outros constantes das leis e das regras aplicáveis de direito internacional. § 2. Os preceitos constitucionais e legais relativos aos direitos fundamentais devem ser interpretados e integrados de harmonia com a Declaração Universal dos Direitos do Homem".

A própria DUDH de 1948 é a síntese de milhares de anos de conquistas em termos de Direitos Humanos e, nos tempos mais recentes, constitucionais. O seu artigo

\footnotetext{
${ }^{1}$ Prof.-Adj. e Coord. das Ciências Jurídico-Fundamentais na Escola Superior de Gestão do IPCA (Minho, Portugal). Prof.-C. no Mestrado na Universidade do Minho. Investigador do CEDU-Centro de Estudos em Direito da União Europeia. Doutor e Licenciado pela Faculdade de Direito da Universidade de Coimbra. Mestre pela Faculdade de Direito da Universidade Católica Portuguesa. Presidente da C.F.D. do Sindicato Nacional do Ensino Superior. gsopasdemelobandeira@ hotmail.com Twitter@gsdmelobandeira ${ }^{2}$ Fica aqui a nossa homenagem ao Sr. Prof. Catedrático Doutor Paulo Ferreira da Cunha pelo nobre trabalho que tem feito em prol do Tribunal Constitucional Internacional, da Faculdade de Direito da Universidade do Porto, bem como de duas Universidades Brasileiras: Anhembi-Morumbi e FADISP, ambas da região do Estado de São Paulo.

3 Constitucional duas vezes porque, como bem se sabe, não é por uma norma e/ou princípio ser "constitucional do ponto de vista formal" que, de modo necessário passa a ser constitucional do ponto de vista material. CANOTILHO (2003, 2015), passim; ou (2008); ou (2012). CUNHA (2013).
} 
$1^{\circ}$ será uma das suas, e nossas, referências fundamentais: "Todos os seres humanos nascem livres e iguais em dignidade e em direitos. Dotados de razão e de consciência, devem agir uns para com os outros em espírito de fraternidade".

A metodologia que foi seguida prendeu-se com a investigação comparativa sobretudo dogmática e doutrinal ${ }^{4}$, legal ${ }^{5}$, mas também, ainda que brevitatis causa, jurisprudencial, ${ }^{6}$ que existe sobre a matéria, como por exemplo, em países como Portugal ou Brasil.

\section{2 - Tribunal Constitucional Internacional-primeiros desenvolvimentos}

Não há direitos e deveres constitucionais sociais fundamentais concretizados sem uma correcta construção e aplicação dos direitos constitucionais (constitucionais). A existência dum Tribunal Constitucional Internacional poderia ajudar a alcançar melhor esse objectivo. E nada disto coloca em causa - bem pelo contrário -, o art. $8^{\circ}$ da Declaração Universal dos Direitos do Homem de 1948: "Toda a pessoa tem direito a recurso efectivo para as jurisdições nacionais competentes contra os actos que violem os direitos fundamentais reconhecidos pela Constituição ou pela lei". O Tribunal Constitucional Internacional seria um promotor deste mesmo art. $8^{\circ}$. Assim como de toda a Declaração Universal dos Direitos do Homem de 1948.

A título exemplificativo, não podemos deixar de destacar as seguintes normas jurídicas internacionais da DUDH de 1948, quer motivos de aplicação concreta e efectiva dos direitos (e deveres), liberdades e garantias constitucionais, quer por causa do direito (e dever) à segurança social.

Assim, temos o art. $11^{\circ}$ da DUDH de 1948, o qual é fundamental em termos de direito penal e/ou criminal constitucional, precisamente a diferença entre a ditadura e o Estado de Direito social democrático, livre e verdadeiro: "1. Toda a pessoa acusada de um acto delituoso presume-se inocente até que a sua culpabilidade fique legalmente provada no decurso de um processo público em que todas as garantias necessárias de defesa lhe sejam asseguradas. § 2. Ninguém será condenado por acções ou omissões que, no momento da sua prática, não constituíam acto delituoso à face do direito interno ou internacional. Do mesmo modo, não será infligida pena mais grave do que a que era aplicável no momento em que o acto delituoso foi cometido".

\footnotetext{
${ }^{4}$ Em termos de relação entre direitos fundamentais constitucionais e direito penal e/ou criminal, mas também de relação entre bens jurídicos individuais e colectivos, com dignidade constitucional e penal e/ou criminal, BANDEIRA (2008, pp. 67-121); ou (2011, pp. 391-430); ou (2015); ou (Responsabilidade, 2015, passim).

${ }^{5}$ Não só, mas também, a Constituição da República Portuguesa de 1976 actualizada; ou a Constituição da República Federativa do Brasil de 1988 com as devidas actualizações. Quando dizemos "actualizada" ou "actualizações", não quer dizer que estejamos de acordo com a constitucionalidade (constitucional) de todas e quaisquer umas que foram realizadas. Umas foram aliás mais consensuais do que outras. Poderíamos aqui nos referi a muitas outras Constituições por esse mundo afora e nomeadamente dentro da União Europeia: os casos paradigmáticos da Lei Fundamental da República Federal da Alemanha ou, da agora muito comentada, Constituição da Hungria.

${ }^{6} \mathrm{Em}$ Portugal, são fartas as referências jurisprudenciais recentes ao nível do Tribunal Constitucional como por exemplo: Acórdão do T.C. $n^{\circ}$ 353/2012, de 5/7; Ac. do T.C. $n^{\circ}$ 187/2013, de 5/4; Ac. do T.C. $n^{\circ}$ 612/2013, de 26/9; Ac. do T.C. $n^{\circ}$ 413/2014, de 30/5. Ou, no que se refere aos projectos do governo PSD/CDS de criminalização do "enriquecimento ilícito" ou criminalização do "enriquecimento injustificado", os quais foram ambos reprovados pelo T.C.: Ac. do T.C. $n^{\circ}$ 179/2012, de 4/4; e Ac. do T.C. $n^{\circ} 377 / 2015$, de 27/7. No Brasil, com relação directa ou indirecta com a aplicação e direitos constitucionais fundamentais e, por exemplo, a aplicação de normas de garantias criminais: Supremo Tribunal Federal-Recurso Ordinário em Habeas Corpus RHC 124082 DF (STF), de 5 de Fevereiro de 2015; Tribunal Regional Federal-Apelação Criminal ACR 37609820064014100, de 24 de Novembro de 2014. No presente momento a "operação lava jato", mas já antes o "mensalão" também adquiriram uma importância fundamental nestas matérias.
} 
Lembre-se uma velha frase que aprendemos com Jorge de Figueiredo Dias e Manuel da Costa Andrade: "Diz-me que processo penal tens e dir-te-ei em que tipo de Estado político vives". Ora, em muitos ordenamentos jurídicos do dito "primeiro mundo", continuam a ser violados os mais elementares direitos fundamentais e direitos humanos, individuais ou colectivos.

Por outro lado, não é possível passar ao lado do destaque social e económico que existe com naturalidade no chamado Estado de Direito social democrático, livre e verdadeiro: veja o art. $22^{\circ}$ da DUDH de 1948. Refere o seguinte: "Toda a pessoa, como membro da sociedade, tem direito à segurança social; e pode legitimamente exigir a satisfação dos direitos económicos, sociais e culturais indispensáveis, graças ao esforço nacional e à cooperação internacional, de harmonia com a organização e os recursos de cada país". Ora, nos tempos mais recentes é muito comum vermos determinados actores políticos a ameaçar as suas populações referindo que "a segurança social está falida, pelo que não haverá futuro, além de terem que efectuar constantes cortes nas pensões"; "não há alternativa". Quando, por curiosidade, e em simultâneo, se gastam milhares de milhões de euros e dólares em parcerias públicoprivadas de obras públicas gigantescas e inúteis, contratos futuros de permuta financeira swap altamente favoráveis a certos privados - em detrimento do interesse público - e/ou rendas artificiais concedidas a empresas que já apresentam lucros de terror social. Tudo isto, por mera coincidência, sempre em prejuízo do erário público e das contas públicas.

Ora, todos nós sabemos que nem todos os Tribunais Constitucionais de todo o mundo têm à sua disposição uma Constituição típica dum Estado de Direito social, democrático, livre e verdadeiro. Assim como, tendo essa suposta Constituição à disposição, aplicam-na de modo interpretativo sui generis e sem uma qualquer possibilidade de recurso a nível mundial. Enfim, a nível europeu, poderíamos evocar, em certa perspectiva, o Tribunal Europeu dos Direitos Humanos (TEDH). Contudo, não podemos pensar de modo egoísta, pensando que o mundo é apenas a Europa. Além de que o TEDH não é um Tribunal Constitucional. Neste desiderato também, nada melhor do que a existência dum Tribunal Constitucional Internacional que viria colmatar essa ausência de referência mundial.

E porque não, já agora, também um Tribunal de Contas Internacional, mas com poderes efectivos de sancionar com retribuição, prevenção geral e especial positivas e, nos casos aplicáveis, justiça restaurativa. Tratar-se-ia aqui, afinal, da afirmação da teoria da necessidade, adequação, proporcionalidade e intervenção mínima tão caras, por exemplo, à CRP: art. $18^{\circ}$ e art. $32^{\circ} / 10$ da CRP. O Tribunal Constitucional Internacional também poderia ser um instrumento interessante em relação ao problema de diferença de tratamento estatal entre as receitas tributárias por parte do Estado e a utilização constitucional (constitucional) dos dinheiros públicos. Deverá existir ou não existir um limite para o défice inscrito na Constituição? E se for inscrito como deve ser interpretado? ${ }^{7}$

\section{3 - Tribunal Constitucional Internacional-segundos desenvolvimentos}

A criação dum Tribunal Constitucional Internacional não é uma utopia. ${ }^{8}$ Falamos de realismo e de rigor jurídico em contraponto. Como diz uma velha frase de cariz profundo científico-interpretativo, "não há nada mais prático do que uma boa teoria". Aliás, são já milhões as referências, v.g., no google sobre o Tribunal Constitucional Internacional, em diferentes línguas. O Tribunal Constitucional

\footnotetext{
${ }^{7}$ Sobre esta questão, BANDEIRA (Responsabilidade, 2015, passim).

${ }^{8}$ Cunha $(2015$, passim).
} 
Internacional deverá surgir como uma antítese dos Estados-de-não-direito-nãodemocráticos-não-livres-e-não-verdadeiros, rectius, das ditaduras. $\mathrm{A}$ eventual aplicação dos direitos nacionais, pelo Tribunal Constitucional Internacional, não será um facto a colocar totalmente de lado. É evidente que ainda não estão resolvidas todas as questões, como por exemplo as que são relativas às adesões de Estados independentes e se podem, ou não podem, colocar reservas. Será preciso, por conseguinte, delimitar bem quais são as competências deste Tribunal Constitucional Internacional. Em termos de competência, teremos que harmonizar com precisão as competências dos tribunais nacionais, regionais e o Tribunal Constitucional Internacional. A competência deste tribunal é, por lógica, uma competência internacional e supranacional.

Cremos contudo que a delimitação negativa não deverá, nem poderá, excluir por completo as questões atinentes ao direito criminal ou certas categorias de direitos humanos. ${ }^{9}$ Como aliás fomos supramencionando. Trata-se, enfim, dum Tribunal Constitucional. Que, ainda mais, é Internacional. Neste sentido, e apenas neste sentido, concordamos que deve ser circunscrita uma competência positiva. Mas esta competência positiva não será nunca absoluta ou eterna, como aliás é timbre das competências de delimitação positiva. Paulo Ferreira da Cunha ${ }^{10}$ chama a atenção para uma diferenciação que é e que poderá ser muito relevante: o juízo de declaração de inconstitucionalidade normativa e o juízo de anti-constitucionalidade fáctica.

Salva melhor opinião, pensamos todavia que o Tribunal Constitucional Internacional deverá abarcar apenas o julgamento de normas jurídicas, de diplomas legislativos, de regulamentos, de despachos, entre outros vértices similares do ponto de vista jurídico; e não de factos ou de pessoas de modo directo. Embora, como é óbvio, uma situação tem sempre influência na outra. Não é contudo uma posição consensual. ${ }^{11}$ É consensual todavia que seja utilizada uma linguagem técnica e conceptual jurídica bem precisa e rigorosa. Além de que deverá ser realçada a diferença entre aquilo que é uma Constituição programa, uma Constituição balanço e uma Constituição material. Deverá também existir uma capacidade de acção e eficácia constitucionais. Ou seja, o Tribunal Constitucional Internacional tem que ser credível, claro e persuasivo, como nos diz Paulo Ferreira da Cunha. Dever-se-á verificar uma interoperabilidade normativa evitando uma "guerra", pensamos também nós, de juízes e juízos. Flexibilidade em relação à arbitragem e conciliação também não será algo a colocar fora de hipótese. A graduação dos direitos e a hierarquia constitucional, na nossa opinião, não deve desrespeitar ou ir além daquilo que a Declaração Universal dos Direitos do Homem de 1948 proclama. O Tribunal Constitucional Internacional deverá surgir como um reforço dos próprios Estados de Direito democráticos, livres e verdadeiros. Sendo que a expressão "Estado de Direito" terá que ser integrada quer nos sistemas de direito continental europeu, quer nos sistemas de direito anglosaxónico, quer nos sistemas de direito africanos, quer nos sistemas de direito do Médio Oriente, quer nos sistemas asiáticos, entre outros possíveis e localizados do ponto de vista jurídico e científico. Será um Tribunal Constitucional Internacional para países grandes e pequenos, de tal modo apelativo, que nenhum quererá pretender ficar de fora. Efeitos como por exemplo a anulação de eleições funcionarão como sanções efectivas e não apenas decorativas ou do género "direito sancionatório simbólico". $\mathrm{Na}$ nossa opinião propomos que eventuais lacunas ou ambiguidades sejam supridas pela DUDH de 1948. Poderá haver reservas nacionais de competência, embora a título de princípio de subsidiariedade.

\footnotetext{
${ }^{9}$ Neste ponto, com uma opinião mais definida, CUNHA (2015, passim).

${ }^{10}$ Idem ibidem.

${ }^{11}$ Noutro sentido, CUNHA (2015, passim).
} 
Deveremos estar neste Tribunal Constitucional Internacional perante uma autoridade consagrada do ponto de vista formal. Sendo que, autonomia do direito, e competência exclusiva, são importantes. Quem não acredita na autonomia do direito pois porventura não deverá acreditar neste projecto. Mas, a História demonstra que não acreditar na autonomia de um direito ético leva-nos a caminhos muito dolorosos para a Humanidade.

\section{4 - Conclusões}

Como nos refere Paulo Ferreira da Cunha, isto é ir fazendo história. A proposta da existência dum Tribunal Constitucional Internacional não será um oásis, mas deverá ser uma resposta à cidade fantasma que é a ausência de ideias, o deserto das ideias, a falta de ideias, a falta de soluções. O cepticismo metódico sem ver terra à vista. A ameaça à paz mundial e aos seus principais protagonistas, dizemos nós também. Liberdade, acção, pensamento crítico. Todos estes factos são importantes.

O Tribunal Constitucional Internacional saberá bem que para além dos poderes judicial, legislativo e executivo, existem poderes como é o caso do poder económico ou do poder da comunicação social. E a liberdade de expressão, tão cara à comunicação social, como espírito hegeliano total da "consciência do mundo" é um dever kantiano ao som de Zorba o Grego, ou Zeca Afonso, com um poema de Brecht.

Se a criação do Tribunal Constitucional Internacional é uma utopia então nós somos utópicos. E damos graças a Deus, e/ou ao Grande Arquitecto, ou como the queiram chamar, por isso. Citando o Papa Francisco em visita aos EUA, Setembro de 2015, "rezem por mim e se não crêem, ou não querem rezar, desejem-nos bem". Internacional.

Neste caso desejem bem ao sonho que é construir um Tribunal Constitucional

\section{5 - Bibliografia}

ALARCÓN, Pietro de Jesús Lora. In: Ciência Política, Estado e Direito Público $\S$ Uma Introdução ao Direito Público da Contemporaneidade, Prefácio: Celso Antônio Bandeira de Mello, $2^{\text {a }}$ edição, Editora Verbatim, 2014.

ALBUQUerQue, Paulo Pinto de. In: Comentário do Código Penal à luz da Constituição da República e da Convenção Europeia dos Direitos do Homem. Lisboa: Universidade Católica Editora, Lisboa, 2010. 4. ed. Reimpressão, 2011.

ALVES, Fernando de Brito, In: Democracia À Portuguesa § Retórica democrática na tradição jurídica lusófona, Editora Lumen Juris, Direito, Rio de Janeiro, 2014.

ANDRADE, Manuel da Costa. In «A "dignidade penal" e a carência de tutela penal como referência de uma doutrina teleológica-racional do crime», RPCC, ano 2, fascículo 2, 1992.

In: A nova lei dos crimes contra a economia à luz do conceito de bem jurídico, Direito Penal Económico, Coimbra: CEJ, 1985; ou in "A nova lei dos crimes contra a economia (Dec.-Lei 28/84, de 20 de Janeiro) à luz do conceito de bem jurídico" in IDPEE (Org.). Direito Penal Económico e Europeu: Textos Doutrinários. Coimbra: Coimbra, 1998. v. I, p. 389 e ss. e 398 e ss. 
BANDEIRA, Melo. In: Acórdão do STJ, de 25.05.1979, "Despedimento nulo"; "Responsabilidade disciplinar do trabalhador"; votação por Unanimidade. BMJ n. 287, a. 1979, p. 190 ou <www.dgsi.pt $\geq$.

BANDEIRA, Gonçalo N.C. Sopas de Melo. Responsabilidade Penal Económico e Fiscal dos Entes Colectivos § À Volta das Sociedades Comerciais e Sociedades Civis sob a Forma Comercial, Coimbra: Almedina, 2004.

A Honra e a Liberdade de Expressão - Acórdão do Supremo Tribunal de Justiça, Jurisprudência Crítica. RPCC - a. 16 - Fascículo 4, Coimbra: Coimbra, out./dez. 2006/2007. p. 643 e ss.

O Direito Penal entre "Creutzfeldt-Jakob e Günther Jakobs"! Ou o Direito Penal (Económico) como Tutela de Bens Jurídicos e a Responsabilidade dos Entes Colectivos no Seio do Direito Penal (da Sociedade) do Risco e do "Direito" Penal do Inimigo», «Estudos Jurídicos Criminais, in AA.VV., Coordenador Luciano Nascimento Silva, Curitiba, Brasil, Juruá Editora, 2008, pp. 67-121;

O Crime de "Branqueamento" e a Criminalidade Organizada no Ordenamento Jurídico Português no contexto da União Europeia: novos desenvolvimentos e novas conclusões. In: AA.VV., Coordenação de NASCIMENTO SILVA, Luciano; BANDEIRA, Gonçalo N.C. Sopas de Melo. Lavagem de Dinheiro e Injusto Penal - Análise Dogmática e Doutrina Comparada Luso-Brasileira. Curitiba: Juruá, Disponível em: <www.jurua.com.br>, 2009.

O Crime de "Branqueamento" e a Criminalidade Organizada no Ordenamento Jurídico Português no contexto da União Europeia: novos desenvolvimentos e novas conclusões. In: AA.VV., Coordenação de NASCIMENTO SILVA, Luciano; BANDEIRA, Gonçalo N.C. Sopas de Melo. Branqueamento de Capitais e Injusto Penal - Análise Dogmática e Doutrina Comparada Luso-Brasileira. Lisboa: Juruá, Disponível em: <www.jurua.com.br>, 2010.

. «Poderá ser a Criminalização do Assédio Moral e/ou mobbing, rectius no trabalho, respeitadora dos princípios constitucionais da necessidade, adequação, proporcionalidade e intervenção mínima penais? - A Lesão dos Direitos Fundamentais Constitucionais dos trabalhadores: o caso português», in Revista «Estudios Penales y Criminológicos», FERNANDO VÁZQUEZ-PORTOMEÑE SEIJAS, Instituto de Criminologia, Faculdade de Direito da Universidade de Santiago de Compostela, pp. 391-430, 2011.

. Abuso de Informação, Manipulação do Mercado e Responsabilidade Penal das "Pessoas Colectivas" - "Tipos Cumulativos" e Bens Jurídicos Colectivos na "Globalização". Edição Revista e Ampliada com Texto Extra. Lisboa: Juruá, 2011/2015 (4 $4^{\mathrm{a}}$ tiragem).

Responsabilidade criminal e recuperação de activos, Colóquio "Direitos Sociais, Gestão Pública e Controlo Financeiro", na Faculdade de Direito da Universidade de Coimbra, com a organização do Tribunal de Contas, do Ius Gentium Conimbrigae e do Institvto Ivridico da Faculdade de Direito da Universidade de Coimbra, ocorrido em 23.04.2014, 9Hrs-18Hrs.

Responsabilidade Financeira e Criminal - Direitos Constitucionais Sociais, Dinheiros Públicos e Recuperação de Ativos - Prefácio de Jónatas Machado", Editora Juruá, Paraná-Curitiba, Brasil e Lisboa, Portugal, 02.2015.

BECCARIA, Cesare. Dei Delitti e Delle Pene e/ou "Dos Delitos e Das Penas" com tradução de José de Faria Costa, do original italiano, Edição de Harlem, Livorno, Itália, 1766. revista por Primola Vingiano, com dois ensaios introdutórios de José de 
Faria Costa e Giorgio Marinucci, Serviço de Educação, Fundação Calouste Gulbenkian, 1998.

BECK, Ulrich. In: Risikogesellschaft. Auf dem Weg in eine andere Moderne. Frankfurt, 1986.

BONAVIDES, Paulo; ANDRADE, Paes de. História Constitucional do Brasil. 6. ed. Brasil: OAB, 2004.

BOTTKE, Wilfried. In: Der Legitimität des Wirtschaftsstrafrechts im engen Sinne und seiner spezifischen Deliktsbeschreibungen, in Bausteine des europäischen Wirtschaftsstrafrechts», Madrid-Symposium für Klaus Tiedemann, Herausgegeben von Bernd Schünemann § Carlos Suárez González, Carl Heymanns Verlag KG • Köln - Berlin • Bonn • München, Alemanha, 1994. p. 109 e ss.

CANOTILHO, J.J. Gomes. In: Direito Constitucional e Teoria da Constituição, $7^{\text {a }}$ Edição, Editora Almedina, ISBN 978-972-40-2106-5, Coimbra, 2003.

CANOTILHO, J.J. Gomes, Estudos Sobre Direitos Fundamentais, Coimbra Editora, Coimbra, $2^{\mathrm{a}}$ Edição, 2008.

CANOTILHO, J. J. Gomes; MOREIRA, Vital. In: CRP § Constituição da República Portuguesa § Anotada § Artigos 1 a 107, 4. ed. rev. Coimbra: Coimbra, 2007. v. I.

. In: CRP § Constituição da República Portuguesa § Anotada § Artigos 108 a 296, 4. ed. rev. Coimbra: Coimbra, 2010. v. II.

In «Brancosos» e Inconstitucionalidade. Itinerários dos Discursos sobre a Historicidade Constitucional, Editora Almedina, Coimbra, Reimpressão da Edição da $2^{\mathrm{a}}$ Edição, 2012.

CARRASQUEIRA, Simone de Almeida. Investimentos das Empresas Estatais e Endividamento Público, Rio de Janeiro: Lumen Juris, 2006.

COELHO, José Carlos. Governo anuncia nacionalização do BPN § Ministro diz que instituição enfrenta "iminente ruptura de pagamentos" § A nacionalização do BPN será a primeira desde 1975. 〈www.publico.pt>, 02.11.2008.

CORREIA, Eduardo H. da S., in Unidade e pluralidade de infracções: a teoria do concurso em direito criminal, Coimbra, Atlântida, 1945.

Eduardo. In: Actas do Código Penal, 1979.

Os artigos $10^{\circ}$ do Dec.-Lei 27 153, 1968.

COSTA, J. Faria, in O branqueamento de Capitais, Algumas reflexões à luz do direito penal e da política criminal, in Boletim da Faculdade de Direito, ano LXVIII.

CUNHA, Paulo Ferreira da, Direito Constitucional Geral - Nova Edição: aumentada, revista e atualizada. 2. ed. Lisboa: Quid Juris, 2013.

La Cour Constitutionelle Internationale (ICCo) - Une Idée qui fait son chemin, CEMOrOC-Feusp / IJI-Univ. do Porto, Notandum 38 mai-ago 2015, passim.

DIAS, Jorge de Figueiredo; ANDRADE, Manuel da Costa. In: Criminologia $\S \mathrm{O}$ Homem Delinquente e a Sociedade Criminógena, 2. Reimpressão (1997), Coimbra: Coimbra, 1992.

Direito Penal § Parte Geral § Tomo I § Questões Fundamentais § A Doutrina Geral do Crime, 2. ed. atual. e ampl. Coimbra: Coimbra, 2007.

FACHIN, Zulmar, Curso de Direito Constitucional, $7^{\mathrm{a}}$ edição revista e atualizada, Editora Forense, Rio de Janeiro, 2015. 
GORJÃO-HENRIQUES, Miguel; MOREIRA, Vital; CANOTILHO, J.J. Gomes; RAMOS, Rui Manuel Moura; ANDRADE, José Carlos Vieira de; RIQUITO, Ana Luísa.

GREENSPAN, Alan. The Age of Turbulence. Adventures in a New World, The Penguin Press, New York, EUA, 2007.

JAKOBS, Günther, In Strafrecht Allgemeiner Teil $\S$ Die Grundlagen und die Zurechnungslehre, Studienausgabe, 2. Auflage, Walter de Gruyter . Berlin . New York, 1993.

JESCHECK, Hans-Heinrich / WEIGEND, Thomas, In Lehrbuch des Strafrechts $\S$ Allgemeiner Teil § Funfte Auflage, Duncker \& Humblot • Berlin, Alemanha, 1996.

JÚNIOR, Salomão Ribas. «O papel do Tribunal de Contas na promoção dos direitos sociais no Brasil», Colóquio Direitos Sociais, Gestão Pública e Controlo Financeiro. Faculdade de Direito da Universidade de Coimbra, com a organização do Tribunal de Contas, do Ius Gentium Conimbrigae e do Institvto Ivridico da Faculdade de Direito da Universidade de Coimbra, ocorrido em 23.04.2014, 9Hrs-18Hrs.

KAUFMANN, Marcel. In: "Europäische Integration und Demokratierprinzip», Baden-Baden Nomos-Verl.-Ges., Studien und Materialien zur Verfassungsgerichtsbarkeit, Bd. 71, 1 Aufl., 1997.

LIMA, F. A. Pires de; VARELA, J. de M. Antunes. In: Código Civil Anotado. (Artigos $1 .^{\circ}$ a $761 .^{\circ}$ ), 4. ed. rev. e atual. com colaboração de M. Henrique Mesquita, Coimbra: Coimbra, 1987. v. I.

LINHARES, Erick. In: A Política Externa da Terra dos Seis Povos § A República Cooperativa da Guiana, Editora Juruá, Curitiba, 2013.

MACHADO, Jónatas E. M.; COSTA, Paulo Nogueira da. In: Curso de Direito Tributário. Coimbra: Coimbra, 2012.

MAHAMUT, María del Rosario García. La Responsabilidad Penal De Los Miembros Del Gobierno En La Constitución, Madrid: Tecnos, 2000.

ROTHENBURG, Walter Claudius. In: Direito Constitucional, Ediora Verbatim, $1^{\mathrm{a}}$ edição, 2010.

SHILLER, Robert J. 1. ed. em 2000; e in Irrational Exuberance, Second Edition, «With new material on the real estate bubble», Currency - Doubleday, New York; London; Toronto; Sydney; Auckland, EUA-RU-Canadá, Austrália, 2005.

SILVEIRA, Edson Damas da. In: Socioambientalismo Amazônico, Editora Juruá, $1^{\text {a }}$ edição de 2008, $2^{\mathrm{a}}$ reimpressão de 2012.

SILVEIRA, Vladmir Oliveira. In: O Poder Reformador na Constituição de 1988 e os limites jurídicos das reformas constitucionais, 1ª edição, São Paulo: RCS, 2006.

STRECK, Lenio Luiz. In: Hermenêutica Jurídica e(m) Crise: uma exploração hermenêutica da construção do Direito, $11^{\mathrm{a}}$ edição, Livraria do Advogado, Porto Alegre, 2014.

WERTENBRUCH, Wilhelm. In: Sozialverfassung, Sozialverwaltung: Ein exemplarischer Leitfaden, zugleich eine Einführung in das Vorhaben eines Sozialgesetzbuches, Athenäum-Verlag, ISBN 3761061641, Frankfurt am Main, 1974. 